\title{
Scenario Forecasting and Monitoring of Regional Development Clusters of Economic Entities
}

\author{
Alexander Sergeevich Rodionov ${ }^{1 *}$, Vladimir Borisovich Soloviev², Evgeny Vasilievich Sukhanov ${ }^{3}$, \\ Nikolay Viktorovich Valuyskov ${ }^{4}$ \\ Financial University under the Government of the Russian Federation, Moscow, Russia \\ ${ }^{2}$ Znanstvene informacije, d.o.o., Ljubljana, Slovenia \\ ${ }^{3}$ Russian Academy of National Economy and Public Administration under the President of the Russian Federation Lipetsk branch, Lipetsk, Russia \\ ${ }^{4}$ Don State Technical University, Rostov-on-Don, Russia
}

Received: $25 / 06 / 2020$

Accepted: 28/09/2020

Published: 20/12/2020

\begin{abstract}
Real-time management becomes a necessary condition for the sustainable development of economic entities in the context of uncertainty. Regional development of the territory includes the creation of clusters to stimulate economic development. The scenario forecasting of the sustainable functioning of economic entities, as well as a proactive risk-oriented approach to strengthening positive trends and reducing negative consequences in the course of implementing decisions, are an important task. Monitoring as a means of conducting continuous gap analysis is an important tool for such management. The authors develop a phenomenological approach to project management in the context of instability and uncertainty of the business environment, to quantum thinking, dynamic planning, and control in the extreme project management.
\end{abstract}

Keywords: Management, Clusters, Scenario forecasting, Sustainable development, Monitoring, Uncertainty, Business environment

\section{Introduction}

The fundamentals of scenario forecasting, one of the everevolving foresight methodologies of the "foresight professor" H.G. Wells (1930), have earned recognition not only among science fiction writers, but also in academic circles. Assessments of the risks of life activity under various scenarios of planetary development are reflected in the fundamental works of scientists and practitioners. Within the framework of this article, the scientific views of J.A. Schumpeter, N.D. Kondratyev, P.A. Sorokin, N.N. Moiseev, P.G. Shchedrovitsky, G.G. Malinetskiy, A. L. Lurie, V.V. Glushchenko, K. Ch. Abta, J. Martino and a number of other public figures are of particular interest. Reports to the Club of Rome being almost annual and published since the late 60 s of the 20th century could serve as an example of an amazing scientific and practical contribution to ensuring the sustainable development of civilization and its secure future.

In 1996, in his publication "Agony of Russia: Does it have a future?", academician N.N. Moiseev attempted to analyze on a system basis the problem of choice [1]. The three decades that have passed since the transformational change called perestroika (1985 -1991), have not given an adequate answer to the problematic questions posed by the academician about a decent future, about country's ability to influence it, and, the most general issue, whether Russia has the right to choose its path, or the country just represents "wagons at the marshaling yard" of the world. The search for a solution still remains extremely relevant.

Scenario forecasting and monitoring of the formation of regional development clusters of economic entities are based on the dualism of divergent and convergent thinking of the decisionmaker. On the one hand, this is a broad opportunity to enter the world system of the sixth technological order of Industry 4.0, while on the other hand, to become a Kenichi Ohmae's cluster [2] of one of the three world empires: the United States of America, Europe, or China. Ohmae's model, according to which a successful strategist should focus on the three "C": Corporation, Customer, and Competitors, has become world-famous. The three "C", like living organisms, constantly interact in a strategic triangle, whose vertices they are. "Mr. Strategy", as one of the five global management gurus according to the Economist Magazine, has maximally simplified the task of globalization and denationalization of economic interests to three " $\mathrm{C}$ ". The cluster is a practical implementation of this paradigm.

\section{Methodology}

The research methodology is based on divergent thinking and phenomenological analysis. This approach is preferable for studying the phase space of events in the near and distant future in conditions of uncertainty and instability (turbulence) of the recent world development environment. The growth of the power of many reference points of bifurcation in decision-making, an

*Corresponding author: Alexander Sergeevich Rodionov, Financial University under the Government of the Russian Federation, Moscow, Russia. E-mail: rodionov.a.s@bk.ru 
obvious drift (approach) to the zones of singular transition to a new quality of civilization development require an instant reaction to the events taking place. The latter is impossible in the context of the differentiation of sciences according to narrow areas of cluster (convergent) thinking without a common integral foresight vision of the planetary development. The primacy of the technocratic approach to the realization of humanitarian values threatens the "robotization" of the human population, its disappearance as a biological species.

\section{Key research issues}

Civilization is entering a new era of its development, namely, information epoch. A unified field theory, in the context of the development of humanity, can be considered as a synergy of three field-based structures: material, energy, and information. When studying the quantum nature of the universe, it has been noticed that the combination of a certain number of similar structural units inevitably leads to the appearance of a new system with new systemic properties. At that, all units of the new structure become its subsystems. The land, material power of the tellurocracy ${ }^{2}$ gives way to the sea energy power of the thalassocracy ${ }^{3}$. Therefore, access to the sea is a key factor for tellurocratic Russia to ensure the life-sustaining activity. The next overwhelming power was air and space, as well as information potency. Atomistic theories of the legally fixed primacy of the interests of the individual over the interests of society in a continuum ${ }^{4}$ of changes lead to the "erosion of law" to the level of egalitarianism. Developing the idea of Karl Schmitt (1988-1985), one of the founders of the war theories, it can be stated that in this case, national, traditional, cultural, professional, and family conditions of preservation, level, way of life, and quality of life disappear.

Taking into account the above, the main issues of the present study were formulated in the Kenichi Ohmae format as five "C" of the national strategy for life safety:

The strategy for selecting the key parameters to assess the life-sustaining activity (LSA);

The strategy for organizing the implementation of key parameters (IKP);

The strategy of motivation and monitoring the IKP and LSA;

The strategy of compliance of IKP and LSA;

Strategy for coordinating the IKP and LSA in real-time mode.

The strategy for selecting the key parameters to assess LSA is based on a phenomenological approach, which in the authors' publications is treated as the Rodionov's paradigm. It is based on a simple idea: the differentiation time in studying sciences according to W. Humboldt (1767-1835) has long passed [3], as well as the division of sciences into natural sciences and humanities of modern age (the beginning of the $16^{\text {th }}-17^{\text {th }}$ centuries), which was the period of rapid development of experimental science in Europe. Today, according to the authors, modern age $\left(19^{\text {th }}-20^{\text {th }}\right.$ centuries $)$ can be called super modern age. In the information age, it is necessary to integrate all the sciences into mega natural science. Recall that classical natural science (nature study) appeared more than 3000 years ago. In those early days, there was no division of real knowledge into natural sciences and humanities. Today, a simple combination of 15 basic disciplines gives more than one trillion new research areas (higher doctoral degree thesis). Today the society returns to the ideas of A. Comte (1798-1857), the founder of positivism and sociology as an independent science. In his classification of sciences (hierarchy or pyramid of sciences), physics was followed by chemistry and biology; while the pyramid of natural sciences was completed by social physics - sociology [4].

Based on Comte's views, the authors added four more sciences to sociology: economics, ecology, cultural studies, and political science. The synergy of the five sciences is called Rodionov's pentahedron [5]. The sector of ecology and economics of life preservation is at the base of pentahedron, economics and sociology are responsible for the quality of life, sociology and cultural studies create people's way of life, while cultural studies and the ecology - life quality. The height of the pentahedron from the intersection point of four diagonals to its top sets the vector of responsibility of political science for the LSA of the economic entity.

The strategy of searching for the cause, deductive (global) thinking, and integral (conceptual) knowledge should replace the content of the contemporary strategy. It is necessary to interrupt the destructive (ostentatious) struggle with the consequence, exclude the inductive (local) approach in solving urgent problems of LSA, and stop in-depth differentiation in the training of narrow-profile specialists who know everything about nothing. It is necessary to enrich the key competencies of training with experience in the possession of key resources in basic activities. In scenario forecasting, it is important to keep in mind that mathematically any movement of a liquid - from a ripple in a puddle to a tsunami - represents a solution to the classical hydrodynamics equations. Initial and boundary conditions determine the cause and nature of the process under study. At that, it is impossible to solve hydrodynamic equations written in general form when considering a particular problem, since certain assumptions should be considered in each specific case. The implications of such assumptions may be of global significance. Computer simulation of weather conducted by E.N. Lorenz has revealed an unexpected "butterfly effect" - the flapping of butterfly wings in Asia may affect the weather in New York [6].

Scenario forecasting of the formation of economic entities development clusters is possible in two ways. One way was considered above. This is the seizure of vital resources, the militarization of the economy and society, and world hegemony. The second way, which Russia has been defending in recent years along with the right to preserve its identity, is the development of the individual and society, general disarmament, and, peaceful coexistence as a final result. Each of the tasks being solved to change the world order, international rules-based system, and outlook includes material (eco-), energy (ergo-), and socioinformation (ego-) aspects; contains the laws (-nomics), science (-logic) and wisdom (-phy) of civilizational development. In the authors' interpretation, the first, material level includes economics, i.e. the laws of coexistence, ecology - the science of survival, and ecosophy - the wisdom of settlement. The second, energy level includes ergonomics - the laws of energy consumption, ergology - the science of power supply, ergosophy

\footnotetext{
${ }^{2}$ Tellurocracy is a type of civilization or state system that is clearly associated with the development of land territories and consistent penetration into inland territories.

${ }^{3}$ Thalassocracy is a state with primarily maritime realms, an empire at sea, or a seaborne empire.

${ }^{4}$ From Latin continuum, meaning continuous, solid.
} 
- the wisdom of power distribution. Finally, the third socioinformational level includes egonomics - the laws of morality (ecological imperative), egology - the science of national culture preservation and development, and egosophy - the wisdom of cultural diplomacy.

The solution to the issue of the future of the global civilization in the context of continuous differentiation of knowledge has lost its primary basis. As the outstanding philosopher and logician of the $20^{\text {th }}$ century, K. Popper (1902-1994) noted, with this approach, each solution to a problem generated new problems [7, p. 274]. The situation is becoming critical. The cumulative effect increases. The intensive use of natural resources is accompanied by environmental pollution. Widespread implementation of scientific and technological progress in the context of quasimarket relations is accompanied by the aggravating of natural, man-made, and socio-economic hazards and shocks. Emergencies that used to happen once every 100 years now occur every 10 years. The consequences are becoming more dangerous for the economy, the population, and the environment. Direct and indirect damages from emergencies reach $4-5 \%$ of the gross national product of the Russian Federation. Given the fact that Russia is rich in natural and human resources, has a huge potential for LSA, it is of undoubted interest for territorial claims, "friendly" or hostile absorption by several militarily strong states of the world. The problems around the Arctic and Antarctic are also becoming quite urgent.

The web-style of safe LSA in the digital economy assumes that the speed of obtaining and amounts of relevant information tend to the maximum, while the time for its awareness for practical implementation is minimized. The open mind and broader vision of an ordinary observer give way to the overmind of an entrepreneur, myth designer with a "sliding horizon (gradient) of planning" for at least five years. Real-time management implies that in a planned "cold" economy, strategic guidelines can be revised every 3-5 years, while for a "warm" market economy - every year. An innovative, "hot" economy requires adjusting five-year goals and targets every quarter. "Plasma digital economy" involves monthly updating of the development strategy for the next five years.

Monitoring of the sustainable development of economic entities (EE) in an uncertain and unstable business environment requires possession of new quantum thinking. In contrast to the linear mechanistic approach of the worldview of the Newtonian era (I. Newton, 1642-1727) [8], the paradigms of Einstein (A.Einstein, 1879-1955) [9], Planck (M. Planck, 1858-1947) [10], and other geniuses of quantum physics qualitatively changed the definitions of the universal laws. Following the logic of D. DeCarlo, the well-known author of the business bestseller "eXtreme Project Management" [11], the decision-maker and the person influencing the decision should freely navigate in two worldview models, two mental realities.

First, it is causative-consecutive thinking, where the life cycle of management has, as it was shown in the works of Harvard School Professor Larry Greiner [12], alternating creative and bureaucratic development phases. His approach to the organization as a living organism ("Evolution and Revolution as Organizations Grow", 1972) is now widely acknowledged. Minimization of any changes so far remains a distinctive feature of the bureaucratic stage, a deterrent of scientific and technological progress (STP), and the main obstacle to the implementation of innovations. The directive plan and its mandatory implementation become the "Bible" of the business organization, the main goal of the economic entity with strict rules and regulations. Material, moral, and career incentives for employees depend entirely on the achievement of targets. Preference is given to a linear and formalized system (standard rules, templates, and procedures).

Second, it is innovative quantum thinking, based on the existence of a dynamic goal that changes its position in space and time. The way to achieve results in such a situation is unpredictable and must change as one gets closer to the goal. The transience of changes and the speed of their appearance becomes the norm of life, while a quick response to them is a condition for survival. The importance and role of decision-makers and the persons influencing the decision are sharply increasing. This concerns any level executives from the CEO of the company to the executive head of the nation. Any mistake or miscount can lead to inevitable consequences. Decision-making executives with the gift of a visionary become highly demanded. The stagnant times have passed, and are now unlikely to ever return. The ability to learn and retrain (Life Live Learning, life-long learning, LLL) becomes mandatory for everyone. Professional knowledge, skills, abilities, art, and mastery can become unclaimed at any time, while the business entity can be declared bankrupt. With the emergence of the Internet, innovation cannot be stopped, and the power of the bureaucracy, as a deterrent on the way of STP, has completely lost its strength. It is useless to struggle against changes; they must be taken for granted. And it is even better to participate directly in their appearance and manifestation. Adaptability is more important than predictability.

In contemporary interpretation, strategy development also requires a certain strategy. One can distinguish five stages of changing the approach to strategy formation. At the first stage, according to IBM (International Business Machines), "The big companies eat up the little ones". In the second stage, according to the BMW (Bavarian Motor Factories), "The fast companies eat up slow ones". At the third stage, as proclaimed by J. Welch (J. Francis "Jack" Welch, Jr., b. 1935) [13], the legendary CEO of General Electric, it is important to be the first. The first, as a rule, always gets $50 \%$ of the niche in the new market. Being an organizer and able to survive is an actual strategy for ensuring a safe life and activity. The concept of the product (service) life cycle of a market economy, which has become a classic, is described in the scientific literature in sufficient detail. One of the first to put it forward in 1965 was the American economist Th. Levitt (1925-2006) [14]. He identified four stages of the product life circle, gave a description of each of the stages, and explained why any product left the market over time. In a simplified form, one can distinguish strategies in marketing, finance, production, and personnel management at the four stages of developing product market: product launch, growth, maturity, and decline. Today, the concept of the product life cycle requires an extended interpretation.

Today, tolerance to changes is a defining feature of the business culture of the future. Its defining features are the principle of delegating responsibility instead of directive management, self-improvement and self-organization, and lifelong learning (LLL). All of the above has already become the reality of today. Classical methods of managing material objects and directing people are no longer effective. "Business @ the Speed of Thought" is not only the title of a bestseller [15] by Bill Gates (1955) but also a key factor in achieving success in the 
business environment. The leadership style in quantum management is characterized by searching for the desired result rather than achieving it. The management methodology consists in monitoring requirements, implementing changes at a high rate, the continuous implementation of innovations, constant technological improvement, and cross-functional organization of the process. Uncertainty management represents the future profession of futurists, who are gradually replacing marketers. The viewpoint of "what is good and what is bad" today depends on the particular situation and the standpoint of what is happening. This is why the cultural aspect of change is so important today, for example, acceptance (the ability to perceive reality as it is) or rejection of such a mass phenomenon as corruption.

The three-hundred-year cycle of classical science development has ended. Newtonian mechanics has been replaced by Einstein's theory of relativity. In the new world of quantum and quark science, the building of the old worldview suddenly became a museum exhibit of scientific achievements, observations and insights, discoveries, and delusions. Over a long time, society rejected everything that seemed to be pseudoscience (cybernetics, genetics, etc.), everything that was not within the framework of law or regularity understandable to every person. Heretics were burned at the stake of the middle ages. Scientists whose views did not fit into the procrustean bed of generally recognized scientific schools were subjected to ridicule. It seemed that one more effort and the world of science would become logical and understandable as clockwork. Economists have already predicted sustainable economic development without crises and shocks. Time has amended. The crises remain. They became a characteristic feature in almost all life spheres. Pseudoscience cybernetics has become an advanced scientific thought, and genetics - the basic technology of the new technological order. The virtual life of society is crowding the real-life activity. Virtual digital (crypto) currency generated by miners "from the vacuum" of computer farms is universally exchanged for real money. Practical experience and laboratory tests gave priority to computational simulations and then cognitive experiments.

Monitoring of the deviation of real changes from expected indicators can be carried out using GAP analysis. Among the identified reasons for deviations, the most common are the following: time delay in implementation; hidden problems that were not identified until the last moment; ineffective coordination in eliminating the identified problems; diversion of forces and funds for the rehabilitation of emergencies; lack of proper professionalism and required competencies (unconscious incompetence), revealed only during the implementation of the tasks being solved; and the impact of uncontrolled factors of the business environment (sanctions, competitors). Moreover, there might emerge other new reasons.

Relatively recently, sociologist Z. Bauman (1925-2017) [16] introduced the concept of Liquid Society (LS) - a society that is in a liquid state, adding this concept to already known two social structures of Land Power and Sea Power. Bauman detected the transition from a dense, structured world, burdened with a whole network of social conditions and obligations to a plastic, fluid world, free of fences, barriers, and borders. In the digital age, getting information does not require direct communication among people. A person isolates from society with the illusion of independence from it. Therefore, education of the sense of responsibility of each person for the world structure and order, outlook, and awareness is very important.

The Quantum World of the civilization progress did not want to limit itself to the procrustean bed of an inanimate machine. The society became aware of its dynamic properties, things disappeared, and emotions revived, the craving for vital energy appeared, and the purposeful search for new building blocks of matter had lost its meaning. Billiard balls moving by the cue and characterized by predicted contact interaction are replaced by the "agents" - positions, impulses, particles, waves, masses, energies, reactions to each other, and the external environment. And all this occurs in the world web of relationships. Today the society is abandoning the concept of predictability and starts thinking about potentials. The Heisenberg uncertainty principle states that one can measure either the particle's aspect or the wave's aspect, i.e. either location or energy, but it is impossible to measure both at the same time.

\section{Conclusion}

The path taken over digitizing the economy can be characterized by the physical laws of motion: uniform (before the 19th century), uniformly accelerated (since 1858), and accelerated (the end of the $20^{\text {th }}$ century). Before the age of the telegraph, this was a "material" process of transmitting information, limited by the speed of the courier service. The electromagnetic telegraph freed information communications from spatial and temporal material restrictions and revolutionized the global economy and social relations. Flows of electric energy, electricity-based way of life allowed the civilization to make a qualitative leap in its development. Air wireless Internet in the 90 s of the $20^{\text {th }}$ century covered the information sphere of the planet with the World Wide Web (www). Today the society lives in the sixth technological order (2010-2050) of the information revolution $[17$, p. 80$]$. Its core is interpenetration or NBICSconvergence (Nano-, Bio-, Info-, Cogito-, Socio-) of nano-, bio-, info- cognitive (thinking), and social technologies. The seventh technological order of civilization development should directly connect human thinking (consciousness) to the infrastructure of Industry N.0 (currently, industry 4.0), bypassing the latent phase of passing knowledge through the filter of science. In the authors' paradigm [18, 19], the key indicators of scenario forecasting of clusters formation of economic entities' LSA are: 1) preserving life and favorable conditions of LSA of both economic entities and population in general; 2) a decent level of LSA; 3) national way of life; 4) quality of LSA. The synergy of four indicators and state compliance is a necessary condition for well-being. Creating clusters seems valuable for the target project, rather than for differentiated narrow areas of LSA. Examples of such integrated clusters today are multi-universities and science towns. Having passed several technological stages, advanced countries are entering the sixth stage of NBICS-technologies, the stage of territorial clusters, virtual reality of the information age, knowledge economy, and reframing of ideas and worldviews. At a time when the amount of information has grown exponentially by six orders of magnitude, education has become imageless and ugly without visualizing the sustainable development of the world in specific images and scenarios of the future. Monitoring the sustainable development of economic entities in the context of uncertainty, extreme management in real-time mode is now a necessary condition for survival and ensuring the safety of the LSA. Planned figures and decision-making management have 
been consigned to history. Quantitative factors of business success are replaced by their qualitative content, which causes an emotional response in both the consumer and the manufacturer of goods and services. The digitalization of goods and services offered by economic entities gives them mental features. Understanding the way of thinking, the general spiritual mood of a person, and groups becomes a driver of sustainable development, determines the market trajectory of the successful promotion of an economic entity in a competitive business environment. The principle, which is brilliant in its predictive value, still needs to be understood in relation to the socio-cultural and economic environment. The destructive emotional energy of the "revolutionary masses" is still more attractive and understandable to the majority of the population. The launch of the energy of creation in anticipation of the embodiment of the "ghost of communism" has exhausted itself. A full-fledged optimistic scenario of world development is needed with clear indication of reference points and singularity zones of the threat to the very existence of mankind.

\section{Ethical issue}

Authors are aware of, and comply with, best practice in publication ethics specifically with regard to authorship (avoidance of guest authorship), dual submission, manipulation of figures, competing interests and compliance with policies on research ethics. Authors adhere to publication requirements that submitted work is original and has not been published elsewhere in any language.

\section{Competing interests}

The authors declare that there is no conflict of interest that would prejudice the impartiality of this scientific work.

\section{Authors' contribution}

All authors of this study have a complete contribution for data collection, data analyses and manuscript writing.

\section{References}

[1] Moiseev NN. Agoniya Rossii: est' li u nee budushchee? Popytka sistemnogo analiza problemy vybora [Agony of Russia: Does it have a future?]. The attempt of system analysis of the choice problem. Green World Newspaper. 1996; Special issue 12:6-15.

[2] Ohmae K. The mind of the strategist: The art of Japanese business. Trans. from English by Yevstigneev I. Moscow: Tochka; 2018.

[3] Hohendorff G. Wilhelm von Humboldt. Perspectives: Issues of education. 2. Thinkers of education. Ed. by Morsi. Moscow; 1994. 3/4(87/88):243-256.

[4] Comte O. The spirit of the positive philosophy: (Word about positive thinking). Translated from the French by Shapiro IA. Rostov-on-Don: Phoenix; 2003. 256 p.

[5] Rodionov AS. Investicii $v$ bezopasnuyu zhiznedeyatel'nost': sohranenie, uroven', uklad, kachestvo [Investment in safe life: Preservation, level, way of life, quality]. Economy. Business. Banks. 2019; 3(29):54-66.

[6] Madrid C. The butterfly and the tornado: Chaos theory and climate change. World of mathematics. Vol. 32. Moscow: De Agostini; 2014.

[7] Popper KR. Objective Knowledge: An Evolutionary Approach. Oxford: Clarendon Press; 2010.

[8] Vavilov SI. Isaak N'yuton [Isaac Newton]. Moscow: Publishing House of the USSR Academy of Sciences; 1945. p. 125-150.

[9] Einstein A, Infeld LM. The Evolution of Physics: The Growth of Ideas from Early Concepts to Relativity and Quanta. Moscow: Nauka; 1965.
[10]Plank M. General Mechanics: Introduction to Theoretical Physics. Part 1. London: Macmillan and Co., Limited; 1932.

[11]DeCarlo D. eXtreme Project Management: Using Leadership, Principles, and Tools to Deliver Value in the Face of Volatility Moscow: Kompaniya p.m. Office; 2005.

[12] Greiner LE. Evolution and Revolution as Organizations Grow. Saint Petersburg University Bulletin. 2002; 2:76-92.

[13] Welch J, Welch S. The Winning. London: Harper; 2007.

[14]Levitt T. Exploit the Product Life Cycle. Harvard Business Review. 1965; 43:81-94.

[15]Gates B. Business @ the Speed of Thought: Succeeding in the Digital Economy. Moscow: Eksmo; 2003.

[16] Bauman Z. Liquid Modernity and Power: A dialogue with Zygmunt Bauman. Journal of Power. 2008; 1(2):111-130.

[17] Glazyev SYu. Strategiya operezhayushchego razvitiya Rossii v usloviyah global'nogo krizisa [Strategy of advanced development of Russia in the context of the global crisis]. Moscow: Ekonomika; 2010. 255 p.

[18]Rodionov AS. Ekonomika chrezvychajnyh situacij: ot likvidacii posledstvij $\mathrm{k}$ normal'noj zhiznedeyatel'nosti [The economy of emergencies: From the elimination of consequences to normal life activity]. Economy. Business. Banks. 2020; 2(40):9-35.

[19] Rodionov AS. Cifrovaya ekonomika v global'nom kontekste [The digital economy in a global context]. Economy. Business. Banks. 2020; 4(42):20-38. 